\begin{tabular}{c|c|c}
\hline \hline & DISEASES OF AQUATIC ORGANISMS \\
Vol. 59: 11-15, 2004 & Dis Aquat Org & Published April 21 \\
\hline
\end{tabular}

\title{
Phylogenetic position of a paramyxovirus from Atlantic salmon Salmo salar
}

\author{
F. Fridell, M. Devold, A. Nylund* \\ Department of Fisheries and Marine Biology, University of Bergen, PO Box 7800, 5020 Bergen, Norway
}

\begin{abstract}
A paramyxovirus has been isolated from Atlantic salmon Salmo salar suffering from epitheliocystis. This virus does not cause any mortality when used to challenge disease-free salmon, but has been associated with 2 cases of mortality in salmon farms in Norway. Atlantic salmon paramyxovirus (ASPV) has been suggested as a name for the virus. The ASP virus is a slow-growing virus in cell cultures (rainbow trout gill cells: RTgill-W1). Little is known about its importance and its phylogenetic position is uncertain. Hence, the need for a fast and sensitive diagnostic method for studying the prevalence of this virus in salmon farms and for more basic knowledge about its identity were the motivation for this study. A partial nucleotide sequence (816 bp) from the large protein (L protein) gene of the ASP virus has been sequenced from 2 different isolates. The putative amino acid sequence has been compared with the L protein of other paramyxoviruses. This sequence gives strong support to a relationship between the ASP virus and members of the subfamily Paramyxovirinae, genus Respirovirus.
\end{abstract}

KEY WORDS: Salmo salar · Paramyxovirus $\cdot$ L protein $\cdot$ Phylogeny Resale or republication not permitted without written consent of the publisher

\section{INTRODUCTION}

Since the start of salmon farming in Norway, there have been reports of epitheliocystis associated with mortalities in farms (Nylund et al. 1998). The agents causing epitheliocystis are intracellular and show morphological features similar to those of Chlamydia and Rickettsia bacteria, but it has not been possible to culture and identify them. In an attempt to culture the bacteria in rainbow trout gill cells (RTgill-W1) (Bols et al. 1994) a research group at the National Veterinary Institute in Oslo Norway, cultured what appeared to be a new paramyxovirus (Kvellestad et al. 2003). Their classification of the virus as a member of the family Paramyxoviridae were based on the morphology of the nucleocapsids and virus particles, virus assembly, and biochemical properties of the virus. They suggested naming the virus Atlantic salmon paramyxovirus (ASPV). Paramyxo- and orthomyxo-like viruses have been described and isolated from several fish species, also from fish with epitheliocystis, but none of these viruses have been genetically characterised (Hoffman et al. 1969, Winton et al. 1985, Fryer 1989, Lannan et al.
1989, Cepeda et al. 1993, Hetrick \& Hedrick 1993, Body et al. 2000).

It is not known what causes mortality in salmon farms where epitheliocystis has been diagnosed, but in some cases viruses have been found in addition to the bacteria (Hoffman et al. 1969, Bradley et al. 1988, Nylund et al. 1998). To determine if the paramyxovirus alone could cause mortalities among salmon, a challenge experiment using the isolate from gills of postsmolts in Norway (Kvellestad et al. 2003) was performed (Fridell 2003). The challenge did not result in any mortality; however, it cannot be excluded that this paramyxovirus may play a role in one or several diseases of salmon in Norwegian aquaculture, and more detailed knowledge about this virus is needed.

Members of the family Paramyxoviridae are enveloped, negative-stranded RNA viruses, and cause some well known diseases of humans and animals (e.g. measles, respiratory syncytial, parainfluenza, mumps, Newcastle disease, rinderpest) (Knipe \& Howley 2001). The Paramyxoviridae is divided into 2 subfamilies, the Paramyxovirinae and the Pneumovirinae. The first contains 3 genera, Respirovirus, Rubulavirus, and 
Morbillivirus, while the latter contains the 2 genera Pneumovirus and Metapneumovirus. In the present study, a partial amino acid sequence from the large L protein (the RNA-dependent RNA polymerase consists of 2 virus-encoded subunits; the phosphoprotein and the L protein) of an ASP virus (Kvellestad et al. 2003) and an identical virus isolated from Atlantic salmon Salmo salar in western Norway, are compared with the L protein of other paramyxoviruses. Nucleotide and amino acid sequences can be good indicators of phylogenetic relationships between viruses (cf. Knipe \& Howlwy 2001). The phylogenetic position of ASPV is discussed.

\section{MATERIALS AND METHODS}

The Atlantic salmon paramyxovirus (ASPV) was first isolated, using rainbow trout gill cells (RTgill-W1, Bols et al. 1994), from gills of farmed Atlantic salmon postsmolts in Norway during an outbreak of gill disease (Kvellestad et al. 2003). The isolate is named ASPV-VI (ASPV-Veterinary Institute) and was used to challenge disease-free salmon in seawater (Fridell 2003). Later the virus was reisolated from the challenged salmon and cultured in RTgill-W1 cells (Fridell 2003). We have also isolated an identical paramyxovirus, ASPV-Ro, from Atlantic salmon suffering from epitheliocystis on the west coast of Norway (Rogaland county).

RTgill-W1 (Bols et al. 1994) cells were cultured in $15 \mathrm{~cm}^{2}$ tissue-culture flasks (Nunc) at $20^{\circ} \mathrm{C}$ in Eagle's minimum essential medium (EMEM) (Sigma) supplemented with $10 \%$ foetal bovine serum (FBS) $(10 \%$ $\mathrm{v} / \mathrm{v})$, L-glutamine $(4 \mathrm{mM})$ and gentamicin $\left(50 \mu \mathrm{g} \mathrm{ml}^{-1}\right)$. The cells were then subcultured for 7 to $10 \mathrm{~d}$ until the tissue flasks were covered with 60 to $80 \%$ confluent monolayer.

Homogenates from ASP virus-infected tissues were diluted 1:100 in phosphate-buffered saline (PBS) and incubated for $1 \mathrm{~h}$ at $15^{\circ} \mathrm{C}$ in cell-culture flasks with the monolayer of RTgill-W1 cells. The inoculum was then removed and replaced by supplemented EMEM as described above, but with $1 \%$ FBS. The cells were incubated for 4 to $8 \mathrm{wk}$ or until a cytopathic effect (CPE) was observed. The cultures were supplied with fresh media at intervals of 1 to $2 \mathrm{wk}$. RNA was extracted from infected cells and reverse-transcribed into cDNA as previously described (Devold et al. 2000, Fridell 2003). A set of internal gene-specific PCR primers (PLF5 and PLR5) was constructed from the published ASP virus sequence AY229974 (Fridell 2003). The primer pair was used on cDNA from ASPV-infected cells and tissues to determine if the ASP virus was present.

Based on existing information that the ASP virus is most probably a paramyxovirus (Fridell 2003, Kvellestad et al. 2003), a selection of L protein gene sequences from paramyxoviruses (Accession Nos. AAC28375, AAD29093, BAA24401, P28887) and related viruses (Filoviridae Accession Nos. AAG40171, P31352, and Rhabdoviridae Accession Nos. BAA25160, P31332) were aligned using the vector NTI Suite software package. The alignment showed areas with conserved amino acid motifs and, using the nucleotide sequences from these areas, new primers were constructed (Table 1). Primers PLF3 and PLR5 were used to obtain an $816 \mathrm{bp}$-long sequence from the L protein of the ASP virus. This partial sequence of the RNA-dependent RNA polymerase gene (L protein) has been deposited in GeneBank under accession No. AY433949.

The PCR products were purified using Qia-quick PCR purification columns (Qiagen) and then sequenced using the Big Dye terminator sequencing kit (Applied Biosystems); 4 templates were sequenced in both directions. Sequence data were assembled with the help of Vector NTI software (InforMax), and GenBank searches were performed using the basic alignment search tool (BLAST 2.0).

The partial amino acid sequence of ASP virus L protein (Accession No. AY433949) was aligned with homologous L protein sequences from a selected num-

Table 1. Degenerate primers used to obtain partial sequence of L protein gene from (ASP) virus, and specific primers directed towards partial L protein gene sequence from ASP virus (Accession No. AY433949). Positions of primers are given in relation to nucleotide sequence of the complete L protein sequence from Sendai virus (Accession No. D00053)

\begin{tabular}{|lcc|}
\hline Name & \multicolumn{1}{c|}{ Primer sequence } & Position \\
\hline PLF1 & 5'-ACA TCA ACW AAT CTM TCM CAT AGG TTA & $3878-3904$ \\
PLF2 & 5'-GGA GGA ATA GAR GGK TWT TGC CAR AAR YTA TGG & $2237-2269$ \\
PLF3 & $5^{\prime}$-TTT CGG ACA TTC GGT CAT CCT & $1110-1129$ \\
PLF5 & 5'-GTA AG GAA CAT AGG GGA TCC & $2876-2895$ \\
PLF6 & 5'-GCA GAA GCT ATG GAC TCT CAT CTC C & $2257-2281$ \\
PLR1 & 5'- WGC MGT RTC YTT TAA CCT ATG & $3916-3896$ \\
PLR2 & 5'-YTG GCA AWA MCC YTC TAT TCC TCC & $2260-2237$ \\
PLR3 & 5'-GTC TCC TTG GAC CAT TGC & $2347-2330$ \\
PLR5 & 5'-ACA GCA GAT ATA CTC TGA GAG TAT GG-3' & $3063-3038$ \\
\hline
\end{tabular}


ber of paramyxoviruses already available on the EMBL nucleotide database (Table 2). To perform pairwise comparisons between the different virus L proteins, the multiple sequence alignment editor GeneDoc (available at: www.psc.edu/biomed/genedoc) was used. In addition to software analysis of the sequences, polymorphic regions were manually aligned and compared for all viruses. Gaps in the alignment were deleted (the alignment can be obtained from the corresponding author).

Phylogenetic analyses of the data sets were performed using PAUP* Version 4.0 (Swofford 1998) and TREEPUZZLE 5.0 (available at: www.tree-puzzle.de). TREEPUZZLE reconstructs phylogenetic trees from molecular data by maximum-likelihood, and computes maximum likelihood distances and branch lengths. In this study, 1000 quartet puzzling (QP) steps were carried out. The QP tree-search estimates support values for each internal branch. Branches showing QP reliability from 90 to $100 \%$ can be considered very strongly supported. Branches with lower reliability (>70\%) can in principle be trusted. For amino acids, we used the VT matrix available in TREE-PUZZLE, which is computed from large set alignments of varying degrees of divergence, for use with proteins of distant relatedness (Muller \& Vingron 2000).

The phylogenetic relationship based on the partial L protein amino acid sequence of the selected paramyxoviruses was also analysed by parsimony using PAUP (1000 bootstrap replicates). However, the only phylogeny presented in this study is the result of analysis using the VT matrix in TREE-PUZZLE, which is recommended for analysis of amino acid sequences (Hall 2001). Phylogenetic trees were drawn using TreeView (Page 1996).

\section{RESULTS}

Using the degenerate primer PLF2 directed against a conserved motif in the sequences of the RNA-dependent RNA polymerase (L protein) gene from a selection of paramyxoviruses, filoviruses and rhabdoviruses, a partial sequence (816 bp) of the L protein gene was obtained from the ASP virus (Accession No. AY433949). PLF5 was used as antisense primer in combination with PLF2. The other degenerate primers did not give any PCR products.

The similarities between the partial $\mathrm{L}$ protein sequence from the ASP virus and members of the Paramyxovirinae ranged from 36 to $63 \%$ across 272 amino acids (Table 3 ). The similarity between the ASP virus and members of the genus Respirovirus ranged from 60 to $63 \%$. The area used in the comparisons relates to amino acids 743-1014 of the L protein of the Sendai virus (BAA24401). This covers the end of Conserved Domain III and about $50 \%$ of Conserved domain IV of the L protein of paramyxoviruses.

Comparisons of the ASP virus nucleotide sequence (816 bp) with that of the Sendai virus (AB005795) gave a similarity of $66 \%$, with a significant part of the variation in the third codon position. The similarity in the third position of the codon was $42 \%$, i.e. $56 \%$ of the difference between the Sendai virus and ASP virus was due to variation in the third position of the codon.

The phylogeny, based on the amino acid sequence from the L protein of the ASP virus (TREE-PUZZLE VT matrix), shows close affinities to Sendai virus (SeV), the human parainfluenza virus (hPIV) Types 1 and 3, and the bovine parainfluenza virus 3 in the genus

Table 2. L protein sequences from a number of selected paramyxoviruses available in EMBL database. These sequences were aligned with that from the ASP viruses isolated from Atlantic salmon

\begin{tabular}{|lcc|}
\hline Virus & Accession No. & Abbreviation \\
\hline Paramyxovirinae & & \\
Unclassified & & \\
Hendra virus & NP047113 & HeV \\
Tupaia paramyxovirus & AAF63393 & TPMV \\
Nipah virus & NP112028 & NiV \\
Morbillivirus & & \\
Canine distemper virus & CAA708042 & CDV \\
Phocine distemper virus & CAA70843 & PDV \\
Measles virus & AAD29097 & MeV \\
Rinderpest virus & P41357 & RPV \\
Rubulavirus (avian genus) & & \\
Newcastle disease virus & AAL09152 & NDV \\
Rubulavirus & & \\
Mumps virus & AAP74199 & MuV \\
Simian parainfluenza virus 5 & Q03396 & SV5 \\
Human parainfluenza virus 2 & NP598406 & hPIV-2 \\
Simian parainfluenza virus 41 & CAA45569 & SV41 \\
Porcine rubulavirus & CAA66807 & PRV \\
Avian paramyxovirus 6 & NP150063 & APV \\
Tioman virus & NP665871 & TV \\
Respirovirus & & \\
Sendai virus & BAA24401 & SeV \\
Human parainfluenza virus 1 & CAA27272 & hPIV-1 \\
Human parainfluenza virus 3 & BAA12219 & hPIV-3 \\
Bovine parainfluenza virus 3 & NP037646 & bPIV-3 \\
Pneumovirinae & & \\
Pneumovirus & & bRSV \\
Bovine respiratory syncytial virus & AAC36684 & AP \\
Human respiratory syncytial virus & P28887 & \\
Metapneumovirus & & \\
Avian pneumovirus & AAB49628 & \\
Human metapneumovirus & NP690071 & \\
& & \\
& & \\
\hline
\end{tabular}


Respirovirus (Fig. 1). The support value (SV) for a membership of the ASP virus in the genus Respirovirus is very high ( $\mathrm{SV}=98)$. Using maximum parsimony in PAUP gave the same phylogeny as the VT matrix in TREEPUZZLE. The support value for ASPV as a member of the Respirovirus, using PAUP, was $89 \%$.

\section{DISCUSSION}

The aquaculture production of Atlantic salmon Salmo salar in Norway is suffering from a range of diseases with unclear or only partly known aetiology. The list of the most serious diseases include haemorrhagic smolt syndrome (HSS) (Nylund et al. 2003), heart and skeletal muscle inflammation (HSMI) (Nylund et al. 2003), Cardiac myopathy syndrome (Ferguson et al. 1990, Nylund 2001), and epitheliocystis (Nylund et al. 1998). The first 3 are believed to be viral diseases, while epitheliocystis has been associated with a group of unidentified intracellelular Chlamydia- or Rickettsia-like bacteria. However, viruses have been associated with some cases of epitheliocystis (Hoffman et al. 1969, Bradley et al. 1988, Nylund et al. 1998), and Kvellestad et al. (2003) isolated a paramyxo-like virus (ASP virus) from gills collected from Atlantic salmon Salmo salar in 1995. The salmon showed gill inclusions indicating epithe- liocystis. Later the same virus was isolated from Atlantic salmon suffering from epitheliocystis in a farm in western Norway (M. Devold unpubl.). Challenge experiments with isolates of this virus did not result in any mortalities, but the virus could still be detected in the challenged salmon after 173 d (Fridell 2003). Even though the virus itself may not cause any mortality in salmon, it cannot be excluded that it may be partly responsible for development of disease in salmon, either in a co-infection with other agents or in situations where environmental stress weakens the immune defence of the salmon. Hence, the present study was designed to generate more basic knowledge about this virus.

\section{Paramyxovirinae}

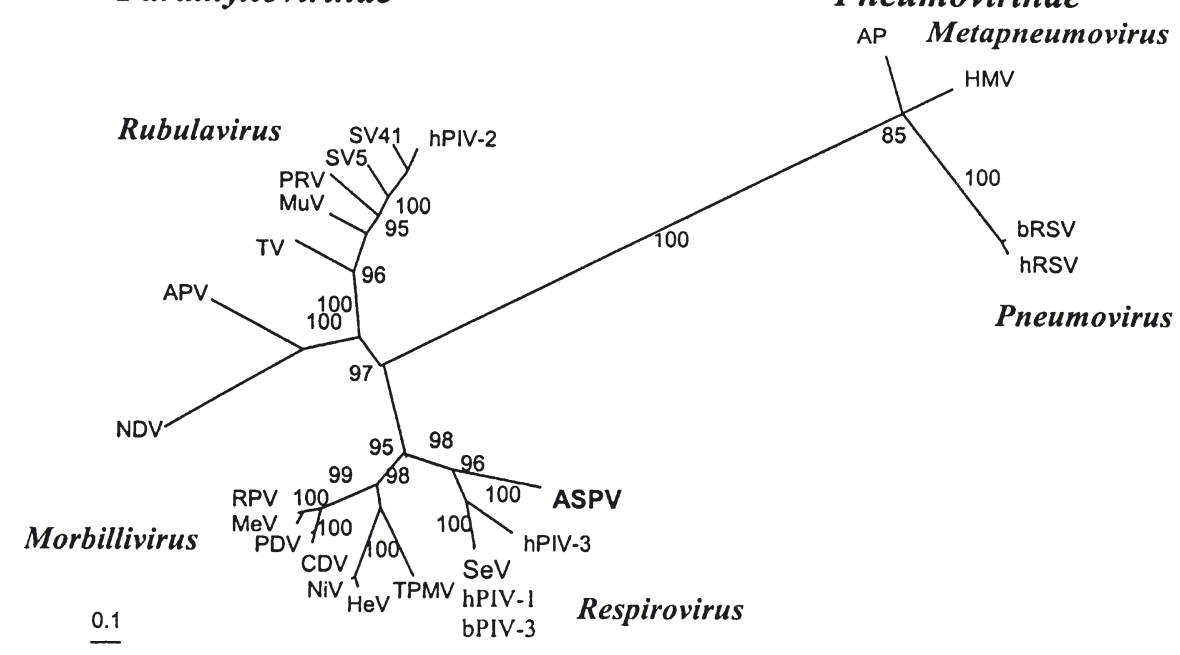

Fig. 1. Phylogenetic position of Atlantic salmon paramyxovirus (ASPV) (AY433949) in relation to other paramyxoviruses (see Table 2). Evolutionary relationship is presented as a maximum likelihood tree based on alignment of a partial sequence of the L protein amino acid sequences from selected family members. Branch lengths represent relative phylogenetic distances according to maximum likelihood estimates base on the VT matrix (Muller \& Vingron 2000). Quartet puzzling (QP) support values are $>90 \%$ for all branching points, the only exceptions being the relationship between the Pneumovirinae (85\%). Scale bar shows number of amino acid substitutions as a proportion of branch lengths 
The family Paramyxoviridae has been divided into 2 subfamilies, the Paramyxovirinae and the Pneumovirinae (Knipe \& Howley 2001), and the former subfamily has been further subdivided into 3 genera, Respirovirus, Rubulaviurs and Morbillivirus. In addition there is a group consisting of the recently isolated Hendra and Nipah virus which are unclassified members of the Paramyxivirinae. This classification is based on morphological criteria, organisation of the genome, biological activities of the proteins, and sequence relationship of the encoded proteins. The evolutionary relationship of members of the Paramyxoviridae based on the nucleocapsid and phosphoprotein amino acid sequences, confirm this organisation (Knipe \& Howley 2001). In the present study another part of the paramyxovirus genome, a partial sequence of the RNA-dependent RNA polymerase (L protein), has been used in a phylogenetic construction of this virus family. The result is the same as that obtained when using the nucleocapsid and phosphoprotein sequences. In this phylogeny the paramyxovirus from salmon (ASP virus) shows a close affinity to the respiroviruses using both TREE-PUZZLE (QP support value $98 \%$ ) and PAUP (bootstrap support value $89 \%$ ) analysis. However, despite the close similarity between the partial L protein sequence from ASP virus and respiroviruses, it is too early to assign this fish virus to this genus. A larger part of the ASP virus genome should be sequenced and used for comparison with other paramyxoviruses. Still, based on the morphology (Kvellestad et al. 2003) and the partial sequence of the $\mathrm{L}$ protein, it can be confirmed that the ASP virus is a member of the subfamily Paramyxovirinae and that it shows affinities with members of the genus Respirovirus.

The partial L protein sequence from the ASP virus is the first identified sequence from a paramyxovirus isolated from a fish. Other studies have shown that paramyxoviruses or paramyxo-like viruses may be widely distributed in fish populations (Hoffman et al. 1969, Winton et al. 1985, Fryer 1989, Lannan et al. 1989, Hetrick \& Hedrick 1993, Body et al. 2000, Kvellestad et al. 2003), and using this first sequence as a starting point it should be possible compare the different isolates. It also opens up the possibility of developing molecular diagnostic methods for fish paramyxoviruses. Such methods would be of vital importance in future studies of epizootics and the role of fish paramyxoviruses in relation to disease.

Acknowledgements. We are greatly indebted to Knut Falk and Agnar Kvellestad at the National Veterinary Institute, Norway, for supplying an isolate of the ASP virus. This work was financed by SAM.

\section{LITERATURE CITED}

Body A, Lieffrig F, Charlier G, Collard A (2000) Isolation of virus-like particles from koi (Cyprinus carpio) suffering from gill necrosis. Bull Eur Assoc Fish Pathol 20:87-88

Bols NC, Barlian A, Chirino-Trejo M, Caldwell SJ, Goegan P, Lee LEJ (1994) Development of a cell line from primary cultures of rainbow trout, Oncorhynchus mykiss (Walbaum), gills. J Fish Dis 17:602-611

Bradley TM, Newcomer CE, Maxwell KO (1988) Epitheliocystis associated with massive mortalities of cultured lake trout Salvelinus namaycush. Dis Aquat Org 4:9-17

Cepeda C, Rivas C, Lamas J, Ledo A, Dopazo C, Toranzo AE (1993) Pathogenicity study of a new viral agent (paramyxovirus) isolated from turbot (samandrag). In: Cervino A, Landin A, deCoo A, Guerra A, Torre M (eds) Fourth National Congress on Aquaculture. Centro de Investigaciones Marinas, Ponteverda, Vilanova de Arouas, Galicia, p 651-655

Devold M, Krossøy B, Aspehaug V, Nylund A (2000) Use of RT-PCR for diagnosis of infectious salmon anaemia virus (ISAV) in carrier sea trout Salmo trutta after experimental infection. Dis Aquat Org 40:9-18

Ferguson HW, Poppe T, Speare DJ (1990) Cardiomyopathy in farmed Norwegian salmon. Dis Aquat Org 8:225-231

Fridell F (2003) Påvisning av paramyxovirus i utvalde vev frå Salmo salar etter eksperimentell smitte. Master thesis, Department of Fisheries and Marine Biology, University of Bergen, Norway

Fryer JL (1989) The paramyxoviruses and orthomyxoviruses. In: Ahne W, Kurstak E (eds) Viruses of lower vertebrates. Springer-Verlag, Berlin, p 302-308

Hall BG (2001) Phylogenetic trees made easy. A how-to manual for molecular biologists. Sinauer Associates, Sunderland, MA

Hetrick FM, Hedrick RP (1993) New viruses described in finfish from 1988-1992. Annu Rev Fish Dis 3:187-207

Hoffman GL, Dunbar CE, Wolf K, Zwillenberg LO (1969) Epitheliocystis, a new infectious diseases of the bluegill (Lepomis macrochirus). Antonie Leeuwenhoek 35: 146-158

Knipe DM, Howley PM (2001) Fields virology. Lippincott Williams \& Wilkins, Philadelphia, PA

Kvellestad A, Dannevig BH, Falk K (2003) Isolation and partial characterization of a novel paramyxovirus from the gills of diseased seawater-reared Atlantic salmon (Salmo salar L.). J Gen Virol 84:2179-2189

Lannan C, Arakawa C, Winton J, Fryer J (1989) Persistent infections of fish cell lines by paramyxovirus isolated from Chinook salmon (Oncorhynchus tsawytscha). In: Ahne W, Kurstarn E (eds) Viruses of lower vertebrates, SpringerVerlag, Berlin, p 309-316

Muller T, Vingron M (2000) Modeling amino acid replacement. J Comput Biol 7:761-776

Nylund A (2001) Hjertesprekk, Kardiomyopatisyndrom (CMS). Fiskehelse 1:29-37

Nylund A, Kvenseth AM, Isdal E (1998) A morphological study of the epitheliocystis agent in farmed Atlantic salmon. J Aquat Anim Health 10:43-55

Nylund A, Plarre H, Hodneland K, Devold M, Aspehaug V, Aarseth M, Koren C, Watanabe K (2003) Haemorrhagic smolt syndrome (HSS) in Norway: pathology and associated virus-like particles. Dis Aquat Org 54:15-27

Page RDM (1996) TREEVIEW: an application to display phylogenetic trees on personal computers. Comput Appl Biosci 12:357-358

Swofford DL (1998) Phylogenetic analysis using parsimony and other methods, Version 4.0. Sinauer Associates, Sunderland, MA

Winton JR, Lannan CN, Pansom DP, Fryer JL (1985) Isolation of a new virus from Chinook salmon (Oncorhynchus tshawytscha) in Oregon USA. Fish Pathol 20:373-380 